\author{
Łukasz Kaźmierski ${ }^{1}$, Anna Bajek ${ }^{1}$, Robert Debski², Magdalena Bodnar ${ }^{3}$, Krzysztof Roszkowski $^{4}$ \\ ${ }^{1}$ Department of Tissue Engineering, Collegium Medicum Bydgoszcz, Nicolaus Copernicus University, Poland \\ 2Department of Pediatric Hematology and Oncology, Collegium Medicum Bydgoszcz, Nicolaus Copernicus University, Poland \\ ${ }^{3}$ Department of Clinical Pathomorphology, Collegium Medicum Bydgoszcz, Nicolaus Copernicus University, Poland \\ ${ }^{4}$ Department of Oncology, Radiotherapy and Gynecologic Oncology, Collegium Medicum Bydgoszcz, Nicolaus Copernicus University, Po- \\ land
}

\title{
Does the conditioned medium trigger the adipose-derived mesenchymal stem cells differentiation into Chondrocytes?
}

\author{
Corresponding author: \\ Krzysztof Roszkowski, Department \\ of Oncology, Radiotherapy \\ and Gynecologic Oncology, \\ Collegium Medicum Bydgoszcz, \\ Nicolaus Copernicus University, \\ Poland \\ e-mail: roszkowskik@cm.umk.pl
}

Medical Research Journal 2018; Volume 3, Number 3, 148-152 10.5603/MRJ.2018.a0025 Copyright (C) 2018 Via Medica ISSN 2451-2591

\begin{abstract}
Background: Cartilage is an avascular tissue that has limited regenerative capacity. Stem cells, especially mesenchymal stem cells (MSCs), have been regarded as a promising cell source for cartilage repair due to their multi-lineage differentiation potential. Induction of mesenchymal stem cells into functional chondrocytes may resolve the above problems in the cartilage repair. However, the imperative is to develop effective strategies for chondrogenic differentiation. The aim of this study is to evaluate if the induction of adipose-derived mesenchymal stem cells (ADSCs) differentiation toward chondrocytes is possible with the use of conditioned medium derived from chondrocytes culture.

Material and methods: Conditioned medium (CM) from Normal chondrocyte cell line CRL 2648 was used to culture ADSCs, at the same time ADSCs with standard growth medium were used as a control. During this experiment, the phenotype was assessed using flow cytometry (CD90, CD44, CD45 and CD45), and Immunohistochemical staining was used to determine differentiation (anti-aggrecan, anti-CD15, anti-collagen II, anti-TRA-2-49). Results: ADSCs propagated rapidly in vitro and formed a homogenous fibroblast-like morphology. $0 \%$ of tested cells showed the expression of CD90 and CD44, while more than 90\% did not reveal the expression of CD34 and CD45. Results obtained in this study showed weak cytoplasmatic expression of aggrecan and alkaline phosphatase (TRA protein) and lack of CD151 expression. However, the majority of ADSCs expanded with CM expressed type II collagen indicating that the chondrocyte-secreted factors induced chondrogenic commitment during expansion.

Conclusions: In the natural environment of living organisms, the chondrogenic differentiation of stem cells involve multiple signalling pathways. We can, to an extent mimic these signals in vitro however, for the clinical purposes it is very important to develop well-defined and efficient in vitro protocols. Our results indicate that $\mathrm{CM}$ may regulate and induce differentiation of ADSCs into the chondrocyte lineage and can serve also as an in vitro model for studying specific lineage commitment.

Key words: cartilage injury, conditioned medium, mesenchymal stem cells, chondrocytes, adipose-derived mesenchymal stem cells
\end{abstract}

Med Res J 2018; 3 (3): 148-152

\section{Introduction}

Traumatic injury and age-related degenerative diseases associated with cartilage are major health problems occurring worldwide $[1,2]$. Cartilage is an avascular tissue that has limited regenerative capacity [3]. However, transplantation of autologous chondrocytes is widely utilized in clinical practice and has reached broad acceptance [4,5]. Nevertheless, this treatment is limited due to only filling small defects, de-differentiation of chondrocytes during in vitro culture or loss of collagen II content [5]. Stem cells, especially mesenchymal stem cells (MSCs), have been regarded as a promising cell source for cartilage repair due to their multi-lineage differentiation potential [6-8]. Furthermore, significant progress has been made in the field of regenerative medicine with the use of mesenchymal stem cells [9]. Induction of mesenchymal stem cells into functional 
chondrocytes may resolve the above problems in the cartilage repair. However, the imperative is to develop efficient strategies for chondrogenic differentiation. Many factors can induce MSCs into chondrocytes, especially growth factors, signal factors and proper microenvironment $[6,10,11]$. Previous studies have investigated that chondrocyte-secreted factors may influence the mesenchymal stem cells via paracrine, juxtracrine or gap-junction signalling pathways $[6,12]$.

The aim of this study is to evaluate if the induction of adipose-derived mesenchymal stem cells (ADSCs) differentiation toward chondrocytes is possible with the use of conditioned medium derived from chondrocytes culture.

\section{Material and methods}

\section{Chondrocyte culture and conditioned medium}

Normal chondrocyte cell line CRL 2648 (ATCC, USA) were cultured using DMEM/Ham's F12 supplemented with $10 \%$ FBS, $5 \mu \mathrm{g} / \mathrm{ml}$ amphotericin B and $100 \mu \mathrm{g} / \mathrm{ml}$ penicillin/streptomycin. The conditioned medium (CM) was harvested every two days, filtered using a syringe filter $(0.22 \mu \mathrm{m})$ and stored at $-20^{\circ} \mathrm{C}$ until use.

\section{Isolation and cultivation of ADSCs}

The Local Bioethical Committee of Nicolaus Copernicus University approved all procedures. Rat ADSCs were obtained from abdominal adipose tissue and washed in PBS with antibiotics: penicillin/streptomycin $(100 \mu \mathrm{g} / \mathrm{ml})$ and amphotericin B $(5 \mu \mathrm{g} / \mathrm{ml})$. Then, tissue was purified from blood vessels and incubated in Collagenase I solution ( $1 \mathrm{ml} / \mathrm{g}$ of tissue) (Sigma, Germany) for $30 \mathrm{~min}$ at $37^{\circ} \mathrm{C}$ with shaking in every $5 \mathrm{~min}$. Digestion process was inhibited by adding an equal volume of culture medium. After that, tissue was filtrated using a $100 \mu \mathrm{m}$ cell strainer (BD Bioscience, USA). The obtained filtrate was centrifuged $350 \mathrm{xg}$ for $10 \mathrm{~min}$ and the cell pellet was washed twice with culture medium. Cells were cultured in DMEM/Ham's F12 supplemented with 10\% FBS (PAA, Austria), 10ng bFGF (Sigma, Germany), amphotericin $B(5 \mu \mathrm{g} / \mathrm{ml})$, penicillin/streptomycin $(100 \mu \mathrm{g} / \mathrm{ml})$ and L-glutamine (PAA, Austria).

\section{ADSCs phenotype analysis}

The phenotype of adipose-derived mesenchymal stem cells was confirmed by examining markers expression (BD Bioscience, USA) with the use of flow cytometry (Tab. 1).

Briefly, cells were resuspended at a density $1 \times 10^{6} \mathrm{cells} / \mathrm{ml}$ in cold PBS containing antibodies according to Table 1. Cells with antibodies were then incubated for $30 \mathrm{~min}$ in $4^{\circ} \mathrm{C}$ in the dark. After incubation, cells were washed three times with PBS and centrifuged at 350xg by $5 \mathrm{~min}$. Flow cytometry analysis was performed on EPICS XL using System 2 Software version 3.0 (Beckman-Coulter, Miami FL, USA).

\section{Induction of differentiation}

Pellets of $3 \times 10^{5}$ ADSCs, after $3^{\text {rd }}$ passage, were formed by centrifugation at $350 \times \mathrm{xg}$ by $5 \mathrm{~min}$ in $15 \mathrm{ml}$ sterile falcons (BD Bioscience, USA). After 24 hours of pre-incubation, the basic medium was removed and ADSCs were subcultivated for 14 days in CM obtained from a culture of normal chondrocyte cell line. Then, pellets were fixed with $10 \%$ buffered paraformaldehyde and analyzed by immunohistochemical. Cells cultured in a basic culture medium served as a control.

\section{Immunohistochemical staining as a detection tool for differentiation}

Immunohistochemical reaction was performed on the cytological material in the form of paraffin cell-blocks with a slice thickness of $3 \mu \mathrm{m}$. Immunohistochemical studies were performed using primary antibodies (Millipore, USA) according to Table 2.

For identification of formed antigen-specific antibody complex, EnVision Anti-Mouse HRP was used (DAKO). Localization of the aforementioned complexes was visualized by 3-3'diaminobenzidine (DAB) as the chromogen.

\section{RESULTS}

\section{Characteristic of adipose-derived mesenchymal stem cells}

ADSCs propagated rapidly in vitro and formed a homogenous fibroblast-like morphology. For phenotypic characterization, ADSCs after the $3^{\text {rd }}$ passage was assessed in expression levels of CD90, CD34, CD45 and CD44. $70 \%$ of tested cells showed the expression of CD90 and CD44, while more than $90 \%$ did not reveal the expression of CD34 and CD45 (Fig.1). Such results indicate the mesenchymal nature of isolated cells.

Table 1. Markers used in flow cytometry

\begin{tabular}{lcc}
\hline Marker & Concentration & Cell localization \\
\hline CD90 & $20 \mu \mathrm{l} /$ test & Cell membrane \\
CD44 & $20 \mu \mathrm{l} /$ test & Cell membrane \\
CD34 & $5 \mu \mathrm{l} /$ test & Cell membrane \\
CD45 & $5 \mu \mathrm{l} /$ test & Cell membrane
\end{tabular}


Table 2. Markers used in immunohistochemistry

\begin{tabular}{lcc}
\hline Marker & Concentration & Time of incubation \\
\hline Anti-aggrecan (AB1031) & $1: 100$ & $30 \min 37^{\circ} \mathrm{C}$ \\
Anti-CD151 (MABT58) & $1: 100$ & 16 hours $4^{\circ} \mathrm{C}$ \\
Anti-collagen II (JBC1778630) & $1: 100$ & 16 hours $4^{\circ} \mathrm{C}$ \\
Anti-TRA-2-49 (MAB4349) & $1: 100$ & $30 \min 37^{\circ} \mathrm{C}$ \\
\hline
\end{tabular}

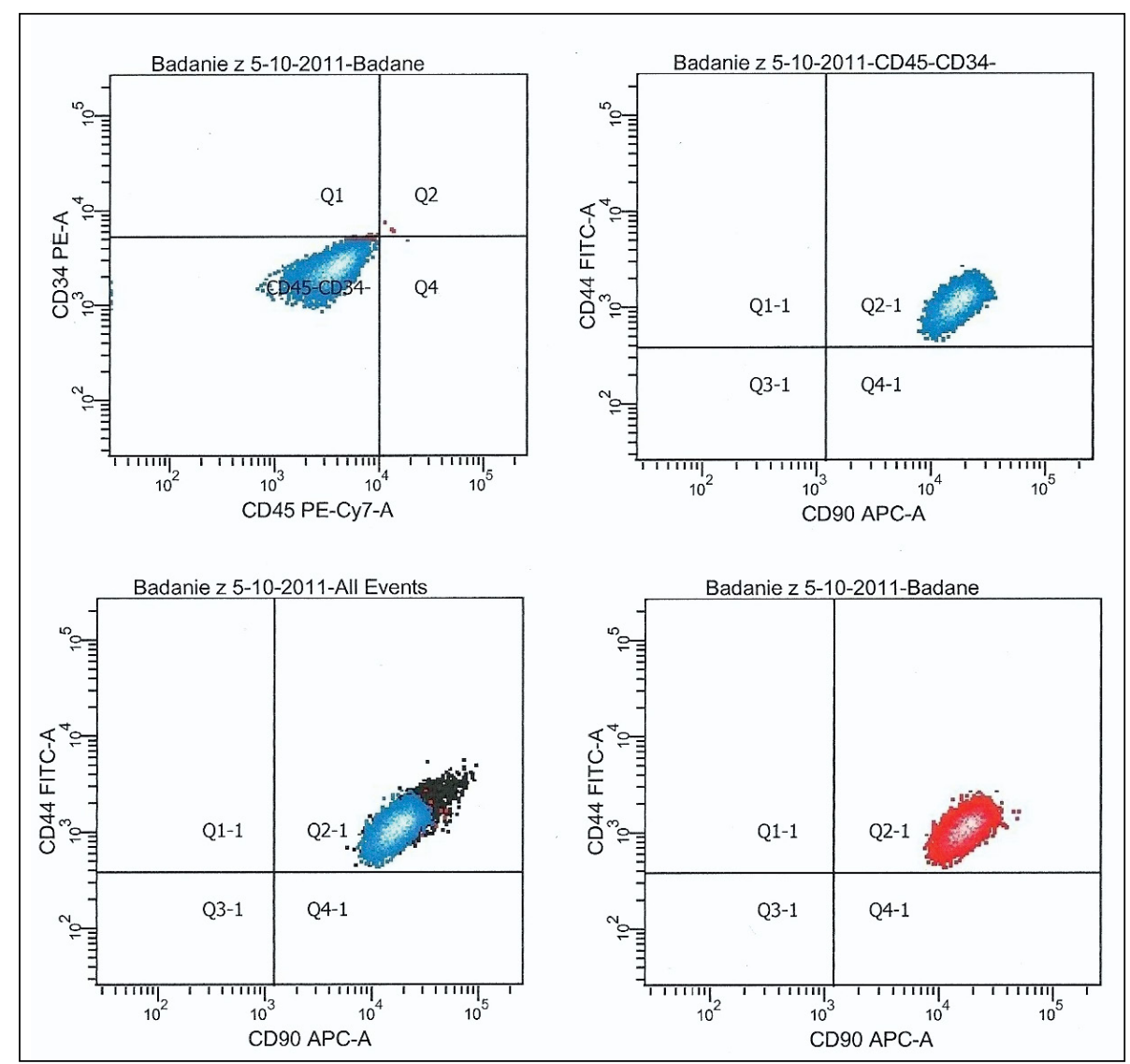

Figure 1. Expression of CD90, CD44, CD34 and CD45 on the surface of ADSCs

\section{Effect of Conditioned Medium on differentiation induction of ADSCs toward chondrocytes}

The initial goal of this study was to determine the chondrogenic commitment of ADSCs in vitro. After 14 days of $\mathrm{CM}$ expansion, the chondrocyte differentiation of adipose-derived mesenchymal stem cells was investigated by immunostaining for type II collagen, aggrecan, CD151 and alkaline phosphatase. Results obtained in this study showed weak cytoplasmatic expression of aggrecan and alkaline phosphatase (TRA protein) and lack of CD151 expression. However, the majority of ADSCs expanded with CM expressed type II collagen indicating that the chondrocyte-secreted factors induced chondrogenic commitment during expansion (Fig.2).

\section{DIscussion}

In attempting to use stem cells for cartilage repair, it is imperative to develop well-defined and efficient protocols for directing stem cell differentiation into the chondrogenic lineage in vitro [1, 2]. Such pre-differentiation in vitro can reduce spontaneous differentiation of stem cells, which are defined as an undifferentiated, in vivo. Moreover, it will result in higher efficiency of transplantation and better integration with recipient tissue. Adult stem cells derived from adipose tissue and bone marrow have shown significant chondrogenic potential $[7,11]$. However, adipose-derived mesenchymal stem cells still remain less well characterized. It is very difficult to elucidate the molecular mechanisms and signalling 


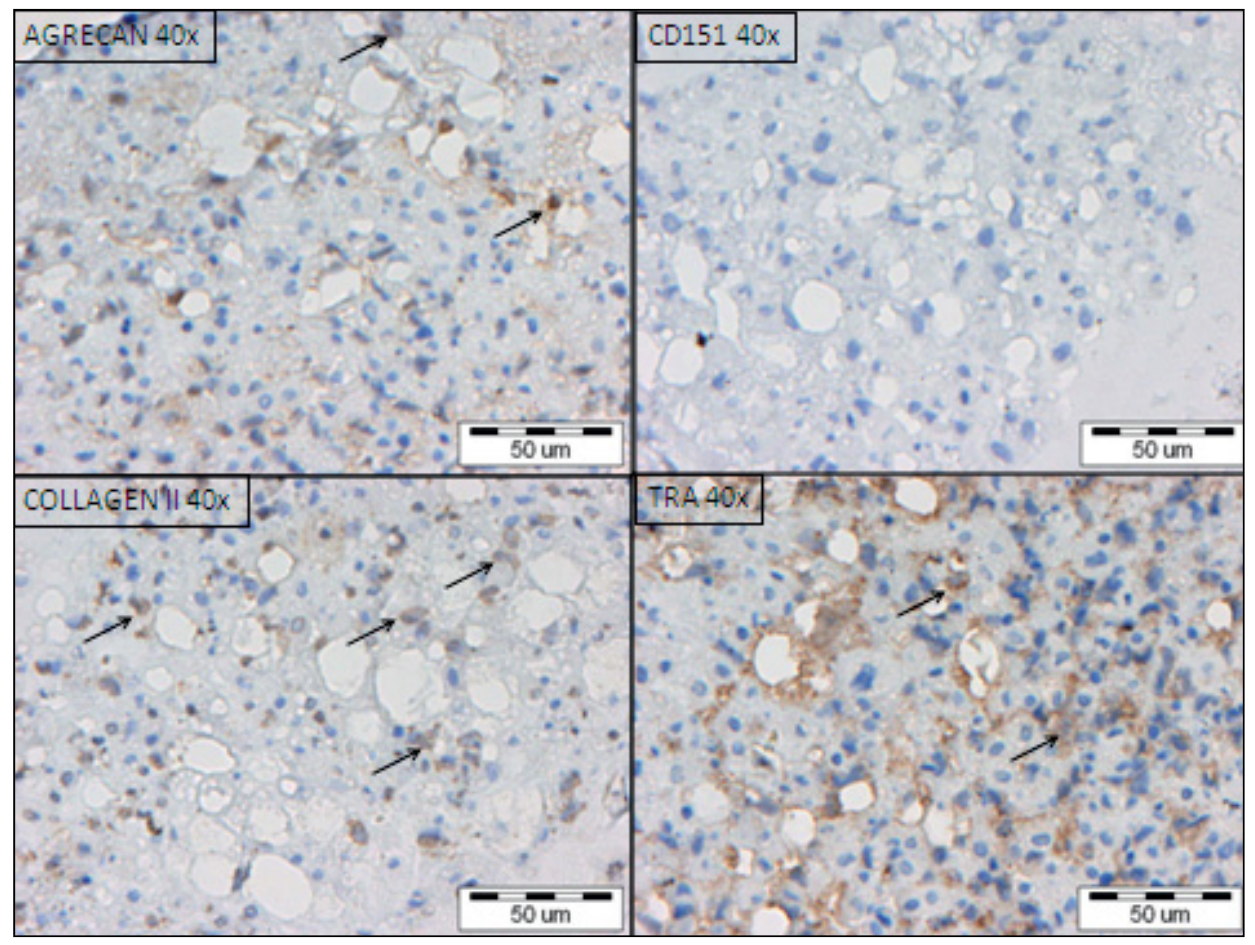

Figure 2. Effects of chondrocyte-conditioned medium (CM) on ADSCs

pathways that regulate chondrogenesis in vivo, within an animal model. There are different experimental models for directing the chondrogenic differentiation of stem cells in vitro, inter alia well-defined culture medium, using of exogenous cytokines and growth factors, co-culture with chondrocyte or genetic manipulation [1]. One of the current approaches includes the use of conditioned media obtained from the culture of normal chondrocytes. That is why the aim of our study was to evaluate if the CM harvested from the normal chondrocyte cell line is a sufficient factor for induction ADSCs differentiation toward chondrocyte phenotype. Previous studies have shown that culture media conditioned by embryonic calvarial cells, embryonic limb bud and perichondrial cells have stimulatory effects on chondrogenesis [13-15]. Liu et al reported that conditioned medium derived from chondrocyte/scaffold constructs induced the bone marrow mesenchymal stem cells differentiation after 4 weeks [16]. Immunohistochemical analysis in our studies revealed the positive staining of collagen II, aggrecan even after 2 weeks of differentiation conditions. Within cartilaginous tissue, the major collagen is collagen type II, whereas the predominant proteoglycan is aggrecan [1, 8]. Expression of these specific for cartilage markers indicates on induction of differentiation process [16]. Weiss et al also defined the chondrogenic differentiation of mesenchymal stem cells as a successful when collagen type II and proteoglycans were detected [4]. Hwang et al gained similar results. However, they also noticed the expression of collagen I and X, which can suggest the hypertrophy of cells [5]. We noticed the weak expression of alkaline phosphate also, although we did not see the decrease in the synthesis of collagen type II. We did not reveal the presence of CD151, which is a surface marker of chondrocytes. However, this marker is often tested in monolayer culture of chondrocytes, its expression can be much less prevalent in pellet culture [17]. Recently, some studies revealed that chondrocytes are capable of producing and releasing numerous growth factors and cytokines, including bone morphogenetic protein-2 (BMP-2), parathyroid hormone (PTH) and TGF- $\beta 1[16,18,19,20,21]$. It is quite probable that they are likely to present in the chondrocyte CM utilized in our study. Nevertheless, we did not make such an evaluation. Liu et al. tested the growth factors present in the $\mathrm{CM}$ derived from human coastal chondrocytes/scaffolds constructs by protein microassay and the CM contained low levels of TGF- $\beta 1,2,3$, IGF- 1 and high levels of IGF-2, FGF-4 and IGFBP4 [4]. It can explain the induction of chondrogenic differentiation of ADSCs, which was revealed in our study. It seems that chondrocyte-secreted factors may be one strategy to in vivo engineer cartilage tissue. Liu et al. also indicated these proteins as agents playing an important role in this process [22]. Although, the exact mechanism of how the soluble factors promote chondrogenic differentiation of stem cells is still unclear. The challenge is also to find an optimized combination of these factors for the promotion of chondrocyte differentiation. It is worth 
noting that the concentration of the aforementioned proteins in the CM is probably much lower than those used for conventional chondrogenic induction [23], but still, the induction of differentiation was possible. The pellet culture also allows physiological 3D cell-cell and cell-matrix interaction [4, 24]. Due to that, all cells may sense the inductive signals from the $\mathrm{CM}$ at the same time even without properly prepared matrix architecture.

Our immunohistochemical analysis of collagen II and aggrecan support the claim that the chondrocyte $\mathrm{CM}$ can be utilized for the efficient cartilaginous tissue formation by ADSCs in vivo. Nevertheless, it is important to note that the use of filtered CM does not alleviate the risk of viral transmission. Also, secreted factors within conditioned media may be labile and not suitable for prolonged durations of in vitro culture [1]. That is why there is a need to further investigate the morphogenetic factors responsible for chondrogenic priming of ADSCs.

\section{CONCLUSIONS}

Despite a large number of studies, the chondrogenic differentiation of stem cells in vitro still requires clarification. In the natural environment of living organisms, the chondrogenic differentiation of stem cells involves multiple signalling pathways. We can, to an extent mimic these signals in vitro however, for the clinical purposes it is very important to develop well-defined and efficient in vitro protocols. Our results indicate that $\mathrm{CM}$ may regulate and induce differentiation of ADSCs into the chondrocyte lineage and can serve also as an in vitro model for studying specific lineage commitment.

\section{REFERENCES}

1. Joggerst SJ, Hatzopoulos AK. Stem cell therapy for cardiac repair: benefits and barriers. Expert Rev Mol Med. 2009; 11 e20, doi: 10.1017/S1462399409001124, indexed in Pubmed 19586557.

2. Nguyen BK, Maltais S, Perrault LP, et al. Improved function and myocardial repair of infarcted heart by intracoronary injection of mesenchymal stem cell-derived growth factors. J Cardiovasc Trans Res. 2010; 3(5): 547-558, doi: 10.1007/s12265-010-9171-0, indexed in Pubmed: 20559784.

3. Shabbir A, Zisa D, Suzuki G, et al. Heart failure therapy mediated by the trophic activities of bone marrow mesenchymal stem cells: a noninvasive therapeutic regimen. Am J Physiol Heart Circ Physiol. 2009 296(6): H1888-H1897, doi: 10.1152/ajpheart.00186.2009, indexed in Pubmed: 19395555

4. He XQ, Chen MS, Li SH, et al. Co-culture with cardiomyocytes enhanced the myogenic conversion of mesenchymal stromal cells in a dose-dependent manner. Mol Cell Biochem. 2010; 339(1-2): 89-98, doi: 10.1007/s11010-009-0372-2, indexed in Pubmed: 20063193.

5. Pittenger M. Sleuthing the source of regeneration by MSCs. Cell Stem Cell. 2009; 5(1): 8-10, doi: 10.1016/j.stem.2009.06.013, indexed in Pubmed: 19570508.

6. Furuta A, Carr LK, Yoshimura N, et al. Advances in the understanding of sress urinary incontinence and the promise of stem-cell therapy. Rev Urol. 2007; 9(3): 106-112, indexed in Pubmed: 17934567.

7. Lennon DP, Caplan Al. Isolation of rat marrow-derived mesenchymal stem cells. Exp Hematol. 2006; 34(11): 1606-1607, doi: 10.1016/j. exphem.2006.07.015, indexed in Pubmed: 17046584
8. Karaoz E, Aksoy A, Ayhan S, et al. Characterization of mesenchymal stem cells from rat bone marrow: ultrastructural properties, differentiation potential and immunophenotypic markers. Histochem Cell Biol. 2009; 132(5): 533-546, doi: 10.1007/s00418-009-0629-6, indexed in Pubmed: 19688349

9. Roura S, Farré J, Hove-Madsen L, et al. Exposure to cardiomyogenic stimuli fails to transdifferentiate human umbilical cord blood-derived mesenchymal stem cells. Basic Res Cardiol. 2010; 105(3): 419-430, doi: 10.1007/s00395-009-0081-8, indexed in Pubmed: 20091315.

10. Carvalho KA, Oliveira L, Malvezzi M, et al. Immunophenotypic expression by flow cytometric analysis of cocultured skeletal muscle and bone marrow mesenchymal stem cells for therapy into myocardium. Transplant Proc. 2008; 40(3): 842-844, doi: 10.1016/j.transproceed.2008.02.053, indexed in Pubmed: 18455032

11. Gallo MP, Ramella R, Alloatti G, et al. Limited plasticity of mesenchymal stem cells cocultured with adult cardiomyocytes. J Cell Biochem. 2007; 100(1): 86-99, doi: 10.1002/jcb.21012, indexed in Pubmed: 16888800.

12. $\mathrm{Kim} \mathrm{H}, \mathrm{Kim} \mathrm{SW}, \mathrm{Nam} \mathrm{D}$, et al. Cell therapy with bone marrow cells for myocardial regeneration. Antioxid Redox Signal. 2009; 11(8): 18971911, doi: 10.1089/ars.2009.2486, indexed in Pubmed: 19203213.

13. Li X, Yu X, Lin Q, et al. Bone marrow mesenchymal stem cells differentiate into functional cardiac phenotypes by cardiac microenvironment. J Mol Cell Cardiol. 2007; 42(2): 295-303, doi: 10.1016/j. yimcc.2006.07.002, indexed in Pubmed: 16919679.

14. Antonitsis P, loannidou-Papagiannaki E, Kaidoglou $A$, et al. In vitro cardiomyogenic differentiation of adult human bone marrow mesenchymal stem cells. The role of 5-azacytidine. Interact Cardiovasc Thorac Surg. 2007; 6(5): 593-597, doi: 10.1510/icvts.2007.157875, indexed in Pubmed: 17670726.

15. Gwak SJ, Bhang SH, Yang HS, et al. In vitro cardiomyogenic differentiation of adipose-derived stromal cells using transforming growth factor-beta1. Cell Biochem Funct. 2009; 27(3): 148-154, doi: 10.1002/cbf.1547, indexed in Pubmed: 19319827

16. Shim WSN, Jiang S, Wong $P$, et al. Ex vivo differentiation of human adult bone marrow stem cells into cardiomyocyte-like cells. Biochem Biophys Res Commun. 2004; 324(2): 481-488, doi: 10.1016/j. bbrc.2004.09.087, indexed in Pubmed: 15474453.

17. Balana B, Nicoletti C, Zahanich I, et al. 5-Azacytidine induces changes in electrophysiological properties of human mesenchymal stem cells. Cell Res. 2006; 16(12): 949-960, doi: 10.1038/sj.cr.7310116, indexed in Pubmed: 17160070.

18. Corti S, Strazzer S, Del Bo R, et al. A subpopulation of murine bone marrow cells fully differentiates along the myogenic pathway and participates in muscle repair in the mdx dystrophic mouse. Exp Cell Res. 2002; 277(1): 74-85, doi: 10.1006/excr.2002.5543, indexed in Pubmed: 12061818.

19. Dai W, Hale SL, Kloner RA. Stem cell transplantation for the treatment of myocardial infarction. Transpl Immunol. 2005; 15(2): 91-97, doi: 10.1016/j.trim.2005.09.004, indexed in Pubmed: 16412954

20. Tomita S, Li RK, Weisel RD, et al. Autologous transplantation of bone marrow cells improves damaged heart function. Circulation. 1999; 100(19 Suppl): II247-II256, indexed in Pubmed: 10567312.

21. Xu W, Zhang X, Qian H, et al. Mesenchymal stem cells from adult human bone marrow differentiate into a cardiomyocyte phenotype in vitro. Exp Biol Med (Maywood). 2004; 229(7): 623-631, indexed in Pubmed: 15229356

22. Liu Yu, Song J, Liu W, et al. Growth and differentiation of rat bone marrow stromal cells: does 5-azacytidine trigger their cardiomyogenic differentiation? Cardiovasc Res. 2003; 58(2): 460-468, indexed in Pubmed: 12757880

23. Wang T, Xu Z, Jiang W, et al. Cell-to-cell contact induces mesenchymal stem cell to differentiate into cardiomyocyte and smooth muscle cell. Int J Cardiol. 2006; 109(1): 74-81, doi: 10.1016/j.ijcard.2005.05.072, indexed in Pubmed: 16122823

24. Baharvand $\mathrm{H}$, Azarnia $\mathrm{M}$, Parivar $\mathrm{K}$, et al. The effect of extracellular matrix on embryonic stem cell-derived cardiomyocytes. J Mol Cell Cardiol. 2005; 38(3): 495-503, doi: 10.1016/j.yjmcc.2004.12.011, indexed in Pubmed: 15733909

25. Bongso A, Fong CY, Gauthaman K. Taking stem cells to the clinic: Major challenges. J Cell Biochem. 2008; 105(6): 1352-1360, doi: 10.1002/jcb.21957, indexed in Pubmed: 18980213.

26. Choumerianou DM, Dimitriou H, Kalmanti M. Stem cells: promises versus limitations. Tissue Eng Part B Rev. 2008; 14(1): 53-60, doi: 10.1089/teb.2007.0216, indexed in Pubmed: 18454634.

27. Hilenski LL, Terracio L, Borg TK. Myofibrillar and cytoskeletal assembly in neonatal rat cardiac myocytes cultured on laminin and collagen. Cell Tissue Res. 1991; 264(3): 577-587, indexed in Pubmed: 1907887.

28. van Dijk A, Niessen HWM, Ursem W, et al. Accumulation of fibronectin in the heart after myocardial infarction: a putative stimulator of adhesion and proliferation of adipose-derived stem cells. Cell Tissue Res. 2008; 332(2): 289-298, doi: 10.1007/s00441-008-0573-0, indexed in Pubmed: 18305959 